\title{
Initial Lessons From the First National Demonstration Project on Practice Transfor- mation to a Patient-Centered Medical Home
}

\author{
Paul A. Nutting, MD, MSPH \\ William L. Miller, MD, $M A^{2}$ \\ Benjamin F. Crabtree, $P b D^{3}$ \\ Carlos Roberto Jaen, $M D, P b D^{4,5}$ \\ Elizabeth E. Stewart, $P b D^{5}$ \\ Kurt C. Stange, $M D, P b D^{6}$ \\ 'University of Colorado Health Sciences \\ Center and Director of Research, Center \\ for Research Strategies, Denver, Colorado \\ ${ }^{2}$ Lehigh Valley Health Network, \\ Allentown, Pennsylvania
}

${ }^{3}$ Robert Wood Johnson Medical School, Department of Family Medicine, Somerset, New Jersey and Cancer Institute of New Jersey, New Brunswick, New Jersey

${ }^{4}$ Department of Epidemiology \& Biostatistics, University of Texas Health Science Center at San Antonio, San Antonio, Texas

${ }^{5}$ Department of Family and Community Medicine, University of Texas Health Science Center at San Antonio, San Antonio, Texas

${ }^{6}$ Departments of Family Medicine, Epidemiology \& Biostatistics, Oncology, and Sociology, Case Western Reserve University, Cleveland, Ohio

Conflicts of interest: The authors make up an independent evaluation team under contract with the American Academy of Family Physicians. The terms of the contract give the authors complete discretion for evaluating and disseminating findings of the National Demonstration Project without review or permission by the AAFP. The authors report no additional conflicts of interest.

\section{CORRESPONDING AUTHOR}

Paul A. Nutting, MD, MSPH

Center for Research Strategies

225 E. 16th Ave, Suite 1150

Denver, $\mathrm{CO}$

Paul.Nutting@CRSLLC.org

\begin{abstract}
The patient-centered medical home (PCMH) is emerging as a potential catalyst for multiple health care reform efforts. Demonstration projects are beginning in nearly every state, with a broad base of support from employers, insurers, state and federal agencies, and professional organizations. A sense of urgency to show the feasibility of the $\mathrm{PCMH}$, along with a 3-tiered recognition process of the National Committee on Quality Assurance, are influencing the design and implementation of many demonstrations. In June 2006, the American Academy of Family Physicians launched the first National Demonstration Project (NDP) to test a model of the PCMH in a diverse national sample of 36 family practices. The authors make up an independent evaluation team for the NDP that used a multimethod evaluation strategy, including direct observation, in-depth interviews, chart audit, and patient and practice surveys. Early lessons from the realtime qualitative analysis of the NDP raise some serious concerns about the current direction of many of the proposed PCMH demonstration projects and point to some positive opportunities. We describe 6 early lessons from the NDP that address these concerns and then offer 4 recommendations for those assisting the transformation of primary care practices and 4 recommendations for individual practices attempting transformation.
\end{abstract}

Ann Fam Med 2009;7:254-260. DOI: 10.1370/afm.1002.

\section{INTRODUCTION}

The patient-centered medical home $(\mathrm{PCMH})$ is rapidly becoming a powerful engine for multiple reform efforts related to health care delivery, reimbursement, and primary care. ${ }^{1-13}$ During the next few years, we can expect thousands of primary care practices to attempt to convert their offices into PCMHs. Demonstration projects are underway in numerous states and supported by amazingly diverse constituencies that include professional organizations, major employers, insurers, Medicare, state governments, not-for-profit foundations, and others. These diverse and rapidly growing efforts are being initiated based on an appealing idea but with little direct empirical support. ${ }^{4,5}$ The PCMH represents an innovative and exciting national conversation that melds core primary care principles, relationship-centered patient care, reimbursement reform, new information technology, and the chronic care model. Unfortunately, the rush to demonstrate operational and financial feasibility of the $\mathrm{PCMH}$, proceeding apace with the recognition process of the National Committee for Quality Assurance (NCQA) ${ }^{14}$ risks premature closure of the larger PCMH conversations and potentially stifles evolution of the PCMH to meet important patient, practice, and system needs.

The "Future of Family Medicine" report $\mathrm{t}^{15}$ was published in 2004 and detailed the "New Model of Family Medicine."16 This report helped to initiate the national conversations leading to the PCMH. The National 
Demonstration Project (NDP) was launched in June 2006 by the American Academy of Family Physicians $^{17}$ to test this new model and was updated to be consistent with the emerging consensus principles of the PCMH. ${ }^{10}$ Thirty-six family practices were selected from 337 practices completing a well-publicized, comprehensive on-line application. Practice selection attempted to maximize a diversity of geography, size, age, and ownership arrangements. For the most part, the participating practices were highly motivated to test the new models of care and in many cases had begun a local process of innovation.

Practices were randomized into either facilitated or self-directed groups. Facilitated practices received ongoing assistance from a change facilitator, as well as on-going consultation from a panel of experts in practice economics, health information technology, quality improvement, and discounted software technology, training, and support. They were also involved in 4 learning sessions and regular group conference telephone calls. Self-directed practices were given access to Web-based practice improvement tools and services, but they did not have on-site assistance. They self-organized their own learning session halfway through the 2-year project and participated in the final learning session.

The NDP officially concluded, after 2 years, in June 2008. The authors of this report make up an independent evaluation team that designed and is continuing to analyze a multimethod assessment of the NDP. The evaluation addresses both the effect of the PCMH model on patient and practice outcomes and the effectiveness of the facilitated intervention in bringing about transformation.

Even though analysis of the NDP is not yet complete, we feel compelled to share early lessons in advance of more-exhaustive mixed methods research reports planned for early next year. As close observers of these practices for 2 years, we have gained a perspective on the implementation process that we feel deserves attention and public discussion even before the final outcome analysis is completed. In the process of working with these practices, our team has seen the day-to-day reality of changing community-based practices into the current idealized model of the PCMH. We have already learned enough from the NDP to identify some potentially dangerous red flags fluttering over the demonstrations just getting underway. Our early analysis raises concerns that current demonstration designs seriously underestimate the magnitude and time frame for the required changes, overestimate the readiness and expectations of information technology, and are seriously undercapitalized. We fear that with current assumptions, many demonstrations place partic- ipating practices at substantial risk and may jeopardize the evolution of the $\mathrm{PCMH}$ as unrealistic expectations set up demonstrations and evaluations for failure.

The lessons described below arise from both the real-time or "live" qualitative analysis conducted during the NDP and the in-depth and comprehensive analysis currently underway. The live analysis included realtime reading of all data and multidisciplinary analysis team discussion in biweekly conference calls, quarterly reports to the NDP board, ${ }_{1}^{18}$ site visits by a member of the evaluation team, 3 analytic retreats, and member checking with NDP facilitators and practice participants to both expand understanding and seek disconfirming data. This special report, based on our ongoing analysis, raises timely concerns and opportunities. The pressure toward widespread adoption of this is model is gaining momentum so rapidly that we feel compelled to share our observations and summarize the early process-evaluation lessons. We describe 6 critical lessons, suggest 4 recommendations for health policy and 4 for practices, and raise hopeful warnings at this critical juncture for primary care reform.

\section{INITIAL LESSONS LEARNED}

\section{Becoming a PCMH Requires Transformation}

Change is hard enough; transformation to a PCMH requires epic whole-practice reimagination and redesign. It is much more than a series of incremental changes. Since the early 1990s, theories of quality improvement emphasizing sequential plan-do-study-act cycles have dominated change efforts within primary care practices. ${ }^{19}$ Many NDP practices initially chose to take this incremental approach-literally checking off each model component as completed. They were soon overwhelmed with complications. Whereas the traditional quality improvement model works for clearly bounded clinical process changes, the NDP experience suggests that transformation to a $\mathrm{PCMH}$ requires a continuous, unrelenting process of change. It represents a fundamental reimagination and redesign of practice, replacing old patterns and processes with new ones. Transformation includes new scheduling and access arrangements, new coordination arrangements with other parts of the health care system, group visits, new ways of bringing evidence to the point of care, quality improvement activities, institution of more point-of-care services, development of team-based care, changes in practice management, new strategies for patient engagement, and multiple new uses of information systems and technology.

These multiple components of a PCMH are highly interdependent. ${ }^{20}$ Each component, when implemented, ripples throughout the practice, affecting all other work 
processes and individual roles. Prior changes require adjustment as new ones are made and practice systems and relationships begin to operate in different ways. Roles of individuals and the practices, sense of identity, and imagination about the meaning of patient care are changed. Most current practice models are designed to enhance physician workflow. The PCMH should be designed to enhance the patient experience. This shift requires a transformation, not an incremental change.

\section{Technology Needed for the PCMH Is Not Plug and Play}

Although most participating practices had an electronic medical record (EMR) at the beginning of the project, an initial strategy of the NDP was to implement further technological enhancements supporting a PCMH (eg, registries, e-prescribing, patient portals, etc) and to use them to reconfigure work patterns. These added features included a range of components, some of which were enhancements to EMR. ${ }^{17} \mathrm{New}$ technology implementation was more difficult and time consuming than originally envisioned. The hodgepodge of information technology marketed to primary care practices resembles more a pile of jigsaw pieces than components of an integrated and interoperable system. A function as seemingly simple as a disease registry was either absent from EMR systems or extremely awkward to activate and required complicated workarounds. Even with discounted pricing and more than usual technical support from vendors, the challenges proved daunting. Making the tasks more difficult was the need to redefine work processes before implementation rather than after. Technology often floundered on the shoals of practice work redesign. This lesson resonates well with the emerging research literature about the EMR in primary care practices. ${ }^{21-24}$

\section{Transformation to the PCMH Requires Personal Transformation of Physicians}

Transformation to a PCMH requires not only implementing new, sophisticated office systems, but also adopting substantially different approaches to patient care. Such a fundamental shift nearly always challenges doctors to reexamine their identity as a physician. For example, transformation involves a move from physician-centered care to a team approach in which care is shared among other adequately prepared office staff. ${ }^{25}$ To function in this team-based environment, physicians need facilitative leadership skills instead of the more common authoritarian ones. A PCMH requires expanding the clinical focus from 1 patient at a time to a proactive, population-based approach, especially for chronic care and preventive services. ${ }^{26,27}$ In addition, physician-patient relationships need to shift toward a style of working in relationship-centered partnerships to achieve patients' goals rather than merely adhering to clinical guidelines. ${ }^{28-30}$

\section{Change Fatigue Is a Serious Concern Even Within Capable and Highly Motivated Practices}

The magnitude and pace of change required to transform into a PCMH produced change fatigue midway through the first year. Transformation occurs, not at a steady and predictable pace, but in fits and starts. After the strenuous task of implementing a particular $\mathrm{PCMH}$ component, the practice had to simultaneously manage the ripple effects, maintain the change, and prepare for the next. The work is daunting and exhausting and occurring in practices that already felt as if they were running as fast as they could. This type of transformative change, if done too fast, can damage practices and often result in staff burnout, turnover, and financial distress. Fortunately, we saw several instances in which the arduous effort of change was punctuated by a breakthrough, a glimmer of insight, and new energy as process change became connected to personal change and to a renewed sense of meaning and purpose.

Learning sessions became important opportunities for practice leaders to reenergize through sharing experiences and providing support. Nevertheless, participants found it challenging to pass this energy on to colleagues when they returned home.

\section{Transformation to a PCMH Is a Developmental Process}

As the NDP progressed, we began to see a distinction between what we have named the practice's "core structure" and its "adaptive reserve." Core structure includes capabilities to manage basic finances and clinical and practice operations during times of stability and modest change. A practice's ability to keep pace with rapid development and change, however, was largely a function of the practice's adaptive reserve. A strong adaptive reserve includes such capabilities as a strong relationship system within the practice, shared leadership, protected group reflection time, and attention to the local environment. ${ }^{31}$ In the beginning of the NDP, practices varied considerably in their adaptive reserve, and that capability was a major determinant of a practice's initial progress. None of the practices, at baseline, had a systematic change management process in place, and few preserved time for planning and reflection. In many practices, change began as an initial flurry of physician-led, just-do-it, top-down actions. Although initially successful in some practices, this approach proved ineffective in the long-term. The intense pace and magnitude of change soon revealed and exacerbated deeper dysfunction within the rela- 
tionship infrastructure of practices, including tension among physicians and among practice staff, ineffective communication patterns, and avoidance of potential conflict and difficult conversations that produced stalemate. Transformation toward a PCMH appears to require a strategic developmental approach that starts with assuring a strong structural core, and then implements smaller changes that help to build the adaptive reserve. Only then can larger, more complex changes begin. Such transformation takes more time than the 2 years allocated to the NDP.

\section{Transformation Is a Local Process}

We observed multiple pathways toward the PCMH, each highly dependent on initial conditions at the local practice, health care system, and community level. Even among the highly motivated NDP practices (both facilitated and self-directed) there was considerable variation in need for assistance, depending on specific challenges and previous experience with change. Facilitated practices received a spectrum of assistance, including a combination of consultation (providing specific information), coaching (assisting physicians and others in personal transformation), and facilitation (addressing a practice's adaptive reserve.) Among the self-directed practices, some believed they would have benefited from assistance but varied in describing what might have helped. Others reported they did better plotting their own course and time frame with reinforcement from their learning session. Practices with strong adaptive reserve were especially able to develop and implement PCMH components that made sense in the context of their unique characteristics and circumstances.

\section{RECOMMENDATIONS FOR SUPPORTING PCMH PRACTICE TRANSFORMATION}

\section{Health Policy Recommendations}

\section{Assure Adequate Financial Resources}

Transforming to a PCMH costs dollars, as well as time and effort, and currently available funds and reimbursements are likely to be inadequate for the transitional costs. We are encouraged by the many diverse pilot funding programs, but more will be necessary. Pilot programs should include up-front capital dollars to help purchase and implement new information technologies and additional ongoing operational dollars to support the personnel changes needed to implement better care management. All the well-supported NDP-facilitated practices were challenged financially by the project.

2. Tailor the Approach to the Practice There are many ways to create a PCMH and many different forms a PCMH may take. Either over- specification of the model or prescribing the pathway for achieving it can be counterproductive, frustrate practice participants, and exacerbate change fatigue. Respect the practice's responsibility for its own destiny. Practices may need assistance, but decisions of what and how and when to change must be theirs. Facilitation, consultation, coaching, learning sessions, and use of Web resources, all have roles. Practices must remain full partners in their learning and development process.

\section{Assist Physicians With Their Personal Transformation}

A substantial barrier to conversion to a $\mathrm{PCMH}$ is the need for most individual physicians to change their professional identity and the socialized ways they currently deliver primary care. It is important for professional organizations that promote $\mathrm{PCMH}$ development to understand their role as much more than advocating for a new reimbursement structure; they should embrace with equal enthusiasm and dedication the need to promote new approaches to doctoring and managing practices and transformation. This endeavor requires new tools, workshops, and other learning and personal development formats to help physicians transform within themselves and in their relationships with their practice partners, patients, health care systems, and communities. Some new doctoring skills required for the PCMH include working in practice teams, managing chronic care using the chronic care model, incorporating population management, using evidence at the point of care, facilitating leadership skills, integrating change management, training staff as peers (ie, adult learning), patient partnering, and thinking outside the examination room.

4. National Committee for Quality Assurance Should Modify its PCMH-Recognition Process

For most practices, full transformation to a $\mathrm{PCMH}$ is likely to require more than the 3 years of the NCQA process. Even in the NDP, with highly motivated and capable practices, full transformation to a PCMH was not achieved within the 2 years of the project because of the multiple challenges of transforming personal, developing teams, recreating job descriptions and work flow, implementing multiple technologies, building adaptive reserve, accommodating change fatigue, adjusting for problems, learning along the way, and maintaining financial integrity. For most practices, this transformation is likely to require an ongoing process.

Practice transformation is a developmental process; recognition and certification should encourage and support a developmental approach. The NCQA has taken the lead in defining some essential components and creating a 3 -tiered, implementation process for recogniz- 
ing a PCMH. ${ }^{14}$ We fear the details of the recognition process may have reached premature closure, ${ }^{4,5}$ however, before the rich data have emerged from the NDP and other current demonstrations. The experience from the NDP clearly suggests becoming a PCMH necessitates that practices work on leadership development, relationship and communication improvements, and other aspects of building adaptive reserve to achieve sustainable success and to avoid unintentional harm to practice, staff, and patients. As further information on the change process becomes available, we strongly encourage the NCQA to reevaluate its PCMH-recognition process and landmarks to encourage and support a more developmental approach at the practice level. Finally, there is need to incorporate more measures of patient engagement and patient-centeredness.

\section{Practice Recommendations}

\section{Establish Realistic Initial Expectations for Time} and Effort Required

Practices should not underestimate the difficulty they face. Practice transformation is a lengthy process, and at times practices will feel like quitting. They should recognize early the need to build better communications, trust, and relationships so the adaptive reserve for change will be up to the challenges. Having an adaptive reserve is paramount to transformation success and may require months or years of hard work to create a strong communication and relationship infrastructure. Wholepractice redesign is different from incremental quality improvement, although reflection on the effect of individual changes and willingness to make further modification are essential. Finally, it is important protect regular time to reflect and learn as a practice. Transformation to a PCMH will require that everyone in the practice to be engaged in the transformation process.

\section{Develop a Practice Technology Plan, Be Flexible and Reflective}

Implementing technology support for a $\mathrm{PCMH}$ consumes an inordinate amount of time, energy, and dollars. Given this level of investment and the interdependencies of the technology components, practices should develop their own plan that projects which technology components they will implement and in what sequence to achieve the care capabilities they desire. Because the technology landscape is changing so rapidly, the plan should be revisited and updated frequently, with reflection incorporated on the experience thus far. For example, it is possible and sometimes preferable to implement e-prescribing, local hospital system connections, evidence at the point of care, disease registries, and interactive patient Web portals without an EMR.

\section{Monitor Change Fatigue}

It will be important for the practice and its external change agents to monitor closely to avoid or detect early any unfortunate change casualties. In the NDP, periodic learning sessions provided an opportunity to reenergize and motivate participants. In some practices a whole-practice retreat addressing and naming what was happening substantially enabled supportive relationships to develop. Do not be surprised if the situation seems worse after the first 6 months to a year; the experience of benefits often takes at least 2 years.

\section{Learn to Be a Learning Organization}

Observations in the NDP practices suggest transformation is more about learning how to become a learning organization, which co-creates an emergent future, than it is about learning from experts on how to build something already known. There is no expert who knows what a PCMH actually looks like. We are all learning together as thoughtful practices around the country transform in their own way and at their own pace. This learning organization model differs appreciably from the conventional expert model and challenges a medical community expecting consultants to come with external expertise and simply fix problems.

\section{HOPEFUL WARNINGS}

In the headlong rush for widespread implementation of the PCMH, it will be important to continue to learn from the change process and how it evolves in diverse local environments and a rapidly changing national context. Is the PCMH the new managed care of the mid-90s, a new savior of primary care that will be implemented in such a way as to undermine and weaken it? What if the technology isn't ready? What if the endeavor is undercapitalized and underreimbursed? What if the insurers continue to hold all the cards? What if disease management indices and short-term costs are measured and promoted over relationships and health status and value? What if, in the name of economy of scale, the scale of implementation at the local level is too big for real personalization of care? What if, in the guise of efficiency and safety, standardization overwhelms the particular? What if the timeline of expectations is too short? Beyond the skeleton of the Joint Principles, ${ }^{10}$ is there even a shared understanding of what the heart and soul of a PCMH really is?

Part of the PCMH's strong appeal, and also what creates confusion, is that it potentially unites 4 compelling areas of health care reform activity. ${ }^{5}$ These areas include research on primary care's value, improved approaches to chronic care, consumerism, and new health care-related information and communication 
technology. There is mounting evidence showing primary medical care's value in assuring a health care system of higher quality at lower cost and with more equity. ${ }^{32,33}$ The primary care and practice characteristics associated with this evidence are first-contact care with easy access, comprehensive care (degree to which primary care clinician provides a broad range of services), sustained partnerships or longitudinal care, coordinated care, and personal or patient-focused care with family and community orientation. ${ }^{34,35}$ In addition, there is growing support for the use of the chronic care model in health systems and primary care practices. ${ }^{26,27}$ These core primary care features and the chronic care model constitute core elements of the medical home concept.

At the same time, consumer-related groups are advocating for better service, partnership, and transparency in health care. Consumers of health care services want the care they want and need when and how they want and need it, as well as access to information necessary to make appropriate choices. This consumerism track informs the patient-centered part of the medical home. ${ }^{13,29,30,36,37}$ New Web-based technologies, electronic clinical information systems, and telecommunications are finally nearing accessibility and utility for both health systems and primary care practices. ${ }^{22-24,38}$ They offer an opportunity for integrating primary care with the rest of our fragmented health care system and for facilitating more engagement of patients in their own care. Future PCMH recognition and certification processes should focus more on patient-centered attributes and the proven, valuable key features of primary care $^{32}$ than on the disease management and information technology features of the PCMH. The PCMH represents the essentials for better primary care, improved delivery of chronic care, and active partnership with an informed patient synergized by appropriate use of information and communications' technology.

The PCMH represents a pivotal turning point for the restoration of a healthy primary care foundation and better health for our nation. Everyone should have a PCMH, and it should be developed primarily to improve health care; payment reform should remain an important secondary goal. ${ }^{2,3}$ In the spirit of seizing this historical moment, we close with some reminders and hopeful warnings. The PCMH will need adequate capital funding from a combination of federal, state, local, insurance industry, and health systems' participation. Having practices front the cost of transformation with the hope of more appropriate reimbursement in the future is unlikely to succeed. We will need more transparency and negotiation of the many hidden agendas, especially among insurers and physicians. We should be wary of industrial-like schemes and excessive use of the language of productivity and efficiency. Primary care, like healthy food, works best at a local and personal level. What is waste on an assembly line is not necessarily waste in a healing relationship; allow for appropriate variability. Stewarding patients toward healthier lives is a deliberate process-stewarding practices toward health and toward becoming a $\mathrm{PCMH}$ is also.

To read or post commentaries in response to this article, see it online at http://www.annfammed.org/cgi/content/full/7/3/254.

Key words: Primary health care; family practice; professional practice; health care delivery

Submitted November 6, 2008; submitted, revised, February 19, 2009; accepted February 25, 2009.

Funding support: Suport for this evaluation was provided by the American Academy of Family Physicians and the Commonwealth Fund. Additional support was provided through a Research Center grant from the American Academy of Family Physicians. A Clinical Research Professorship from the American Cancer Society also supported Dr Stange's participation.

Acknowledgments: The authors would like to express their appreciation for the cooperation and dedication of the physicians and staff of the family practices that participated in the National Demonstration Project. The National Demonstration Project was designed and implemented by TransforMED, formerly a division, and now a wholly owned subsidiary, of the American Academy of Family Physicians.

\section{References}

1. Backer LA. Building the case for the patient-centered medical home. Fam Pract Manag. 2009;16(1):14-18.

2. Fisher ES. Building a medical neighborhood for the medical home. N Engl J Med. 2008;359(12):1202-1205.

3. Iglehart JK. No place like home-testing a new model of care delivery. N Engl J Med. 2008;359(12):1200-1202.

4. Barr MS. The need to test the patient-centered medical home. JAMA. 2008;300(7):834-835.

5. Berenson RA, Hammons T, Gans DN, et al. A house is not a home: keeping patients at the center of practice redesign. Health Aff (Millwood). 2008;27(5):1219-1230.

6. Glendinning D. Higher Medicare pay earmarked for practices in medical home trial. Am Med News. 2008;51(21):.

7. Grumbach K, Bodenheimer T. A primary care home for Americans: putting the house in order. JAMA. 2002;288(7):889-893.

8. Kellerman R, Kirk L. Principles of the patient-centered medical home. Am Fam Physician. 2007;76(6):774-775.

9. Lewis M. Medical home model improves efficiency, docs say. Med Econ. August 15, 2008

10. Patient-Centered Primary Care Collaborative (PCPCC). Joint Principles of the Patient Centered Medical Home. http://www.pcpcc.net/node/14. Accessed Jan 16, 2009.

11. Schoenbaum SC. The medical home: a practical way to improve care and cut costs. MedGenMed. 2007;9(2):28.

12. Sia C, Tonniges TF, Osterhus E, Taba S. History of the medical home concept. Pediatrics. 2004;113(5)(Suppl):1473-1478. 
13. Davis K, Schoenbaum SC, Audet AM. A 2020 vision of patient-centered primary care. J Gen Intern Med. 2005;20(10):953-957.

14. National Committee for Quality Assurance. PPC-PCMH Publications. http://www.ncqa.org/tabid/629/Default.aspx. Accessed Jan 19, 2009.

15. Martin JC, Avant RF, Bowman MA, et al. The future of family medicine: a collaborative project of the family medicine community. Ann Fam Med. 2004;2(Suppl 1):S3-S32.

16. Green LA, Graham R, Bagley B, et al. Task Force 1. Report of the task force on patient expectations, core values, reintegration, and the new model of family medicine. Ann Fam Med. 2004;2(Suppl 1): S33-S50.

17. TransforMED. National Demonstration Project. http://www.transformed.com/ndp.cfm. Accessed Jan 16, 2009.

18. TransforMED. National Demonstration Project Evaluators' Reports. http://www.transformed.com/evaluatorsReports/index.cfm. Accessed Jan 16, 2009.

19. Langley GJ, Nolan KM, Nolan TW, Norman CL, Provost LP. The Improvement Guide: A Practical Approach to Enhancing Organizational Performance. San Francisco, CA: Jossey-Bass; 1996.

20. Miller WL, McDaniel RR Jr, Crabtree BF, Stange KC. Practice jazz: understanding variation in family practices using complexity science. J Fam Pract. 2001;50(10):872-878

21. Crosson JC, Stroebel C, Scott JG, Stello B, Crabtree BF. Implementing an electronic medical record in a family medicine practice: communication, decision making, and conflict. Ann Fam Med. 2005;3(4):307-311.

22. DesRoches CM, Campbell EG, Rao SR, et al. Electronic health records in ambulatory care-a national survey of physicians. N Eng J Med. 2008;359(1):50-60.

23. Hersh W. Health care information technology: progress and barriers. [comment]. JAMA. 2004;292(18):2273-2274.

24. Kush RD, Helton E, Rockhold FW, Hardison CD. Electronic health records, medical research, and the Tower of Babel. $N$ Engl J Med. 2008;358(16):1738-1740
25. Grumbach K, Bodenheimer T. Can health care teams improve primary care practice? JAMA. 2004;291(10):1246-1251.

26. Bodenheimer T, Wagner EH, Grumbach K. Improving primary care for patients with chronic illness. JAMA. 2002;288(14):1775-1779.

27. Bodenheimer T, Wagner EH, Grumbach K. Improving primary care for patients with chronic illness: the chronic care model, Part 2. JAMA. 2002;288(15):1909-1914.

28. Brody H. Relationship-centered care: beyond the finishing school. J Am Board Fam Pract. 1995;8(5):416-418.

29. Marvel MK, Epstein RM, Flowers K, Beckman HB. Soliciting the patient's agenda: have we improved? [see comment]. JAMA. $1999 ; 281(3): 283-287$

30. Tresolini C, and the Pew-Fetzer Task Force. Health Professions Education and Relationship-Centered Care. San Francisco, CA: Pew Health Professions Commission: 1994.

31. Crabtree BF, Miller WL, McDaniel RR Jr, Stange KC, Nutting PA, Jaen CR. Thriving in an unhealthy environment: building adaptive capacity in primary care. J Fam Pract. In press.

32. Starfield B, Shi LY, Macinko J. Contribution of primary care to health systems and health. Milbank Q. 2005;83(3):457-502.

33. Starfield B. Primary Care: Balancing Health Needs, Services, and Technology. New York, NY: Oxford University Press; 1998.

34. Rosenthal TC. The medical home: growing evidence to support a new approach to primary care. J Am Board Fam Med. 2008;21(5): 427-440.

35. Starfield B, Shi L. The medical home, access to care, and insurance: a review of evidence. Pediatrics. 2004;113(5)(Suppl):1493-1498.

36. Frankel RM. Relationship-centered care and the patient-physician relationship. J Gen Intern Med. 2004;19(11):1163-1165.

37. Roter D. The enduring and evolving nature of the patient-physician relationship. Patient Educ Couns. 2000;39(1):5-15.

38. Steinbrook R. Personally controlled online health data-the next big thing in medical care? N Engl J Med. 2008;358(16):1653-1656. 